\title{
MINI-POLL COPING AS AN ALTERNATIVE ATTACHMENT IN TOOTH SUPPORTED OVER-DENTURE PROSTHESIS
}

\author{
Ahmed N. Elsherbini
}

\begin{abstract}
Aim: Comparing the resistant to pull forces between telescopic crown, to the conventional bare root dome shaped abutments to, the new suggestion Mini-Poll coping in tooth supported overdenture.

Materials and methods: A pseudo-realistic model imitating a ridge with the two canines only present was fabricated with heat cured acrylic resin. The canines were prepared to 6 degrees convergence, telescopic crowns were fabricated and tested, then the canines were prepared to the conventional dome-shaped preparation. Then a wax pattern of the Mini-Poll coping like the conventional coping was fabricated but with certain modifications. An undercut is prepared in the wax pattern to engage permanent soft silicon, which was placed in the fitting surface of the prosthesis opposite to the coping. Force gauge device was used to measure the retention force first with telescopic crown then con. dome abutment and then the MiniPoll coping to resist the tissue away movement and pull forces.
\end{abstract}

Results: 100 readings were taken for each group and the retentive mean values were recorded. The mean values of the retention for 3 groups Telescopic crown, conventional Dome and Mini-Poll coping groups were $5.2 \pm 0.222,1.2 \pm 0.167$ and $4.8 \pm 0.113 \mathrm{~N}$ respectively.

Conclusion: Mini-Poll coping is an adequate treatment option in the over-denture cases, as it has high retentive values, can be used in limited inter-arch space, requires low maintenance, protects abutment from caries, and the simplicity of its fabrication.

\section{INTRODUCTION}

An over-denture is indicated when severe loss of teeth is present and the remaining teeth are three or less ${ }^{2}$. Many forms of over-dentures have been advocated for different situations.
Telescopic crown is usually indicated when crown root ratio is favorable as it protects the abutment, no need for endodontic treatment, provides retention and support, but requires adequate interarch space to be indicated ${ }^{7,8}$. When the crown root ratio is compromised a dome shaped abutments are

\footnotetext{
* Lecturer at Modern Sciences and Arts University, Egypt
} 
usually prepared to correct this ratio. The first option is the bare dome shaped root over-denture with an amalgam plug, this is the simplest form, providing enhanced support, but retention is not optimal, and abutments may be susceptible to caries ${ }^{3,4}$. A modification of bare dome shaped abutments is a metallic coping covering the abutments to protect them, the height of the abutment with a coping or without is usually ranges from $2-3 \mathrm{~mm}$ from gingival margin which is adequate for giving support to the prosthesis but the retention is compromised and not adequate. In such case retention will be more dependent on the physical retention means such as atmospheric pressure and saliva film as in complete denture ${ }^{5}$. For retention to be provided the height of the abutment should be increased to $3-4 \mathrm{~mm}$ to provide friction ${ }^{6}$. Another form is the over-denture retained with attachments; numerous attachments have been used with varying success rates, some have proved high performers and improved patients' quality of life, however they had some drawbacks, as wear of retention by time, high maintenance requirements, fracture of the attachment, in addition to their high costs ${ }^{9,10}$. The available attachments are used as retentive means for the prostheses, and support is taken primarily from the residual ridge ${ }^{11}$. The available treatment options when dealing with an over-denture provide either retention or support to the prosthesis, with limited substitutions that provide both actions. Retention can be measured with different devices, such force meter, force gauge, and universal testing machines ${ }^{6,12}$.

The Mini-Poll coping is a modification of the conventional Dome metal coping, after preparation of the root to dome shape, a metallic cap taking shape of the root with height 2-3 mm from proximal sides and $3-4 \mathrm{~mm}$ from bucco-lingually, an overhanging occlusal edge forming an undercut $0.5-1 \mathrm{~mm}$ all around the cap, the Mini-Poll provides retention to the prosthesis as well as to support.

The aim of this study is to compare the resistance to vertical pull forces between the telescopic crown, conventional bare dome shaped root (Con. Dome), and the new suggestion Mini-Poll coping.

\section{MATERIALS AND METHODS}

A pseudo-realistic model imitating a ridge with the two canines only present was fabricated with heat cured acrylic resin VERTEX $^{\circledR}$ Netherlands. Pseudo mucosa imitating the natural mucosa was placed using tissue mimics GENESIS $^{\circledR}$ S. Korea. The canines were prepared to 6 degrees convergence; wax pattern of the telescopic primary coping is made and milled to zero degrees, with $6 \mathrm{~mm}$ height (occluso-gingival). Casting of the wax pattern, milling, finishing, and polishing were done. Secondary coping was made by pattern resin adapted on metallic primary coping, retention pearls were added to the pattern resin to act as beads for retention of the acrylic resin of over-denture to secondary coping. Over-denture was fabricated in the conventional way. Primary coping were cemented to the canines, secondary coping placed on the primary coping, then pick-up of the secondary coping with the over-denture was done. Two Suction discs were cemented to the prosthesis at the lingual aspect of the prosthesis; orthodontic wires were ligated at the center point of the prosthesis, for the measuring tool to hook the over-denture. The model was fixed to the fixed table of Jelenko surveyor. Force gauge device was used to measure the retention force gained by the over-denture from the telescopic crowns. The force gauge was hooked to the orthodontics wire, and pulling action was initiated, 100 readings were taken.

Then the canines wereprepared to the conventional dome-shaped preparation. The wax pattern of the Mini-Poll coping like the conventional metal coping was fabricated but with certain modifications. Wax pattern cap taking curvature of the root with height (occluso-gingival) $2-3 \mathrm{~mm}$ from proximal sides and $3-4 \mathrm{~mm}$ from bucco-lingually, an overhanging occlusal edge forming an undercut $0.5-1 \mathrm{~mm}$ all around the cap. Casting of the wax pattern, finishing and polishing were done to the Mini-Poll. Then the Mini-Poll coping was cemented on the bare dome shaped abutment. Secondary coping were removed from the overdenture, then opposite to the copings grinding was made to make a space for the silicon to 
be placed in the fitting surface of the over-denture. Permanent soft silicon PROMEDICA ${ }^{\circledR}$ Germany, which can retain its elasticity up to 2 years, was placed in the formed spaces, and then the denture was seated on the model with the Mini-Poll copings cemented in place until complete setting of the silicon. The excess of the silicon was trimmed and

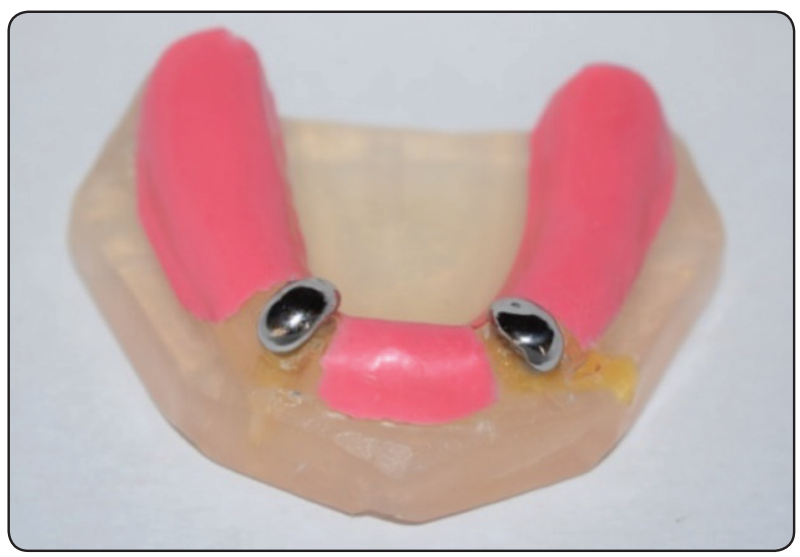

Fig. (1a) Model with Mini-Poll coping cemented

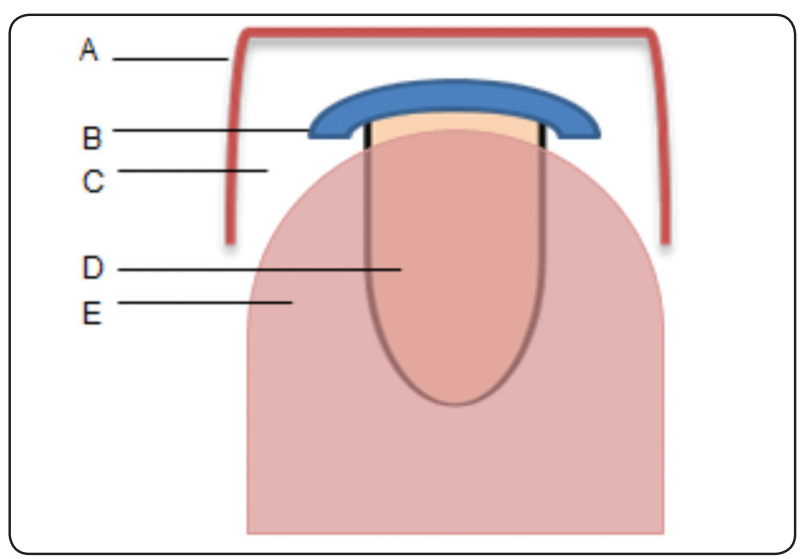

Fig. (1c) Illustrative diagram of Mini-Poll: A- Denture Base, B- Mini-Poll coping (Blue) covering root with an undercut, C- Silicon (White) surrounding the coping and engaging undercut, D- Abutment, E- Residual ridge denture placed back on the model. The force gauge was hooked to the orthodontics wire, and pulling action was initiated, with the Mini-Poll coping to measure the resistance to tissue away movement and Pull forces. 100 readings were taken; data were collected and statically tabulated for both groups (Fig.1a-c).

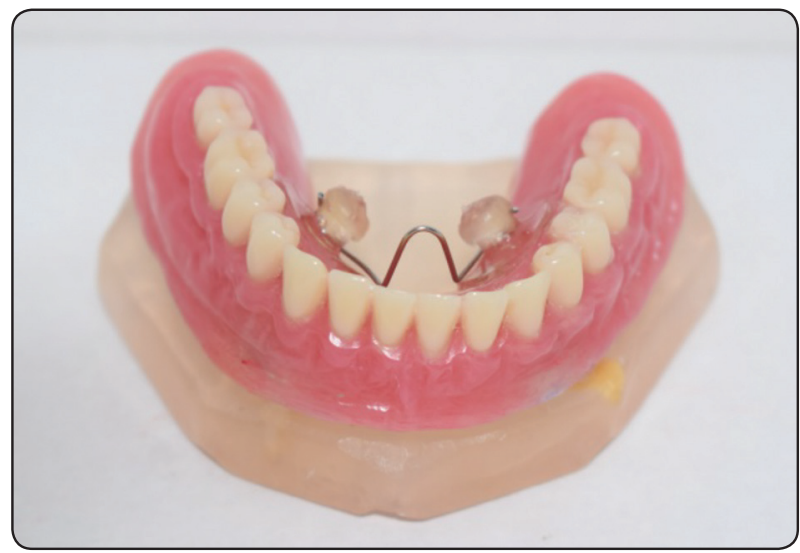

Fig. (1b) Denture with suction discs and orthodontics wire ligated

\section{RESULTS}

Retention force under pulling force for the Telescopic crown, Con. Dome and Mini-Poll coping:

100 readings were taken for each group and the retentive mean values were recorded. The mean values of the retention force for the groups telescopic crown, conventional Dome and MiniPoll coping groups were 5.0 $\pm 0.136,1.2 \pm 0.167$ and $4.8 \pm 0.198 \mathrm{~N}$ respectively. The ANOVA test showed significant difference between the groups with $\mathrm{F}=3.052 \mathrm{P} \leq 0.01$.

TABLE (1) Shows the mean value and standard deviation and errors for groups

\begin{tabular}{|c|c|c|c|c|c|c|c|}
\hline & Mean & Std .Deviation & Std Error & Minimum & Maximum & Range & C.V \\
\hline Con.Abutment & 1.2375 & .16351 & .01635 & .90 & 1.45 & .55 & $2.7 \%$ \\
\hline Teles.Crown & 5.0390 & .10588 & .01059 & 4.85 & 5.20 & .35 & $1.1 \%$ \\
\hline MiniPoll & 4.7878 & .11301 & .01124 & 4.50 & 4.95 & .45 & $1.3 \%$ \\
\hline
\end{tabular}




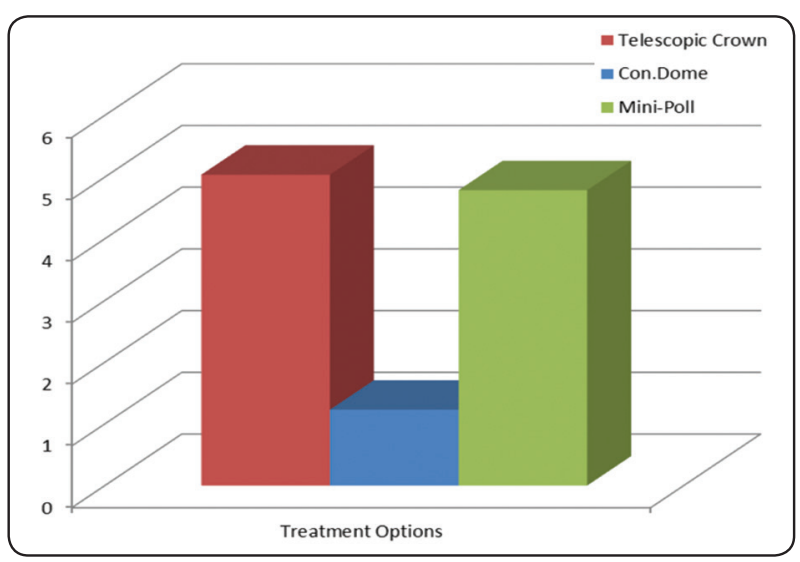

Graph (1) Mean values of the retention force in Newton (N) for the groups telescopic crown, conventional Dome and Mini-Poll coping groups.

\section{DISCUSSION}

Telescopic crown showed higher retention force values when compared with other groups, this is due to the favorable clinical crown length resulting in better friction forces between primary and second copings.

The Mini-Poll coping showed higher retention force values when compared to the conventional Dome, this can be attributed to the direct effect of the coping which increased retention force by engaging the silicon placed in the fitting surface of the prostheses. The silicon in the fitting surface interlocked with the undercut of the Mini-Poll coping resulting in higher retention force values. Whereas, in the conventional dome, the reduced height of the abutment doesn't give adequate friction with the fitting surface of the denture, this is indicated with the lower values of retention force in this group. The values obtained by the Mini-Poll in this study are quite comparable with values obtained by RUTKUNAS AND MIZUTANI, in which they compared magnet attachment with stud attachments in tooth supported over-denture in an in-vitro study ${ }^{12}$, so the retentive factors are the same, which are the direct effect of the attachment used, gravity and adaptation of the denture base to the model ${ }^{13,14}$.
On the contrary, the values are low when compared with MEKAWY et.al, in which they got in the dome shaped abutments values ranging from 3 to $5 \mathrm{~N}$, and when a stud attachment was used values increased to around $6 \mathrm{~N}$ but this was an in-vivo study ${ }^{6}$, so the factors directly affecting the retention are more, such as the saliva film between denture base and tissue, the peripheral seal of the denture borders and the vestibule, and mechanical interlocking between denture base and bony undercuts, interfacial force, oral and facial musculature, and cohesion, beside to other factors, direct effect of the attachment used, gravity, and adaptation of the denture base to the tissue ${ }^{13,14}$.

\section{CONCLUSION}

With the restriction of an in-vitro study, the telescopic crown showed the highest retentive values however has complicated processing procedure and requires adequate inter-arch space, Mini-Poll coping is an adequate treatment option in the overdenture cases, as it has high retentive force values, can be used in limited inter-arch space, requires low maintenance, protects abutment from caries, and the simplicity of its fabrication.

\section{RECOMMENDATION}

It is recommended that further tests to be carried on the Mini-Poll coping but in in-vivo studies.

\section{REFERENCES}

1- Samra RK, Bhide SV, Goyal C, Kaur T. Tooth supported overdenture: A concept overshadowed but not yet forgotten!. J Oral Res Rev 2015;7:16-21

2- Prakash VS, Shivaprakash G, Hegde S, Nagarajappa. Four and two tooth supported - Conventional over denture: Two case reports. Int J Oral Health Sci 2013;3:61-4

3- Khanna TS, Gurav SV, Ram SM, Nandeeshwar DB. Immediate overdenture. J. Contemp Dent 2012;2:101-105

4- Stillwell KD, Amir J. A clinical pathway for complete immediate denture therapy: successful prosthetic management for hopeless dentitions. Gen Dent 2008;6:380-89 
5- Abbas, NA. Complete denture technology, 1st ed. Egypt: MSA University Press; 2008

6- Mekawy NEL, Hegazy S, Raouf C. Impact of Denture Base Materials on Retention of Tooth Retained and Supported Mandibular Overdenture. Periodon Prosthodon. $2015,1: 11$

7- Bayer S., Stark H., Mues S., Keilig L., Schrader A., Enkling N. Retention force measurement of telescopic crowns Clin Oral Invest 2010;14:607-611

8- Elsherbini AN, Niedermeier W., Comparison of Different Methods of Abutment Splinting and Attachments on Teeth Kinetics (Part I). World J Dent 2017;8:352-357

9- Cakarer S, Can T, Yaltirik M, Keskin C. Complications associated with the Ball, Bar and Locator attachments for Implant-supported Overdentures. Med Oral Patol Oral Cir Bucal. 2011;16:953-9.
10- Jayasree K, Bharathi M., Dileep VN, Vinod B, Precision Attachment: Retained Overdenture, J Indian Prosthodont Soc. 2012;12: 59-62.

11- Bansal S, Aras MA, Chitre V, Tooth Supported Overdenture Retained with Custom Attachments: A Case Report J Indian Prosthodont Soc. 2014; 14: 283-286.

12- Rutkunas V., Mizutan H., Retentive and Stabilizing Properties of Stud and Magnetic Attachments Retaining Mandibular Overdenture, An in vitro Study. Stomatologija, Balt. Dent. and Maxillo. J. 2004, 6:85-90

13- Zarb G., Hobkirk JA, Eckert SE, Jacob RF, Prosthodontic treatment for edentulous patients $13^{\text {th }}$ Edition, St. Louis, Elsevier Mosby 2013 P:157

14- Basker RM, Davenport JC, Tomlin HR, Prosthetic treatment of the edentulous patient $3^{\text {rd }}$ Edition, London, Macmillan 1992 P: 56-60 